\title{
Analisis Sungai Ijo Gading Sebagai Daya Tarik Wisata di Kabupaten Jembrana, Bali
}

Anak Agung Ketut Sri Candrawatia, 1, Dinar Sukma Pramesti b, 2

${ }^{1}$ sri.candrawati@pib.ac.id, ${ }^{2}$ dinar.pramesti@pib.ac.id

aProgram Studi DIII Seni Kuliner, Politeknik Internasional Bali, Jalan Pantai Nyanyi, Desa Beraban, Tabanan

bProgram Studi DIV Manajemen Perhotelan, Politeknik Internasional Bali, Jalan Pantai Nyanyi, Desa Beraban, Tabanan

\begin{abstract}
Ijo Gading River is located in a strategic area which cuts across Negara, the capital city of Jembrana Regency, Bali. This river has a great potency to be packed as a tourism destination that can attract tourists to come. To develop the Ijo Gading River as one of tourism destinations, then it is necessary to conduct a research to analyze the internal and external factors possessed by Ijo Gad'ing River as one of tourism destinations at Jembrana, Bali. The results of the research are expected to be considerations for the community, government, and other related parties to develop the potency of Ijo Gading River. This study is a descriptive qualitative research which used observation, interview, literature research, and document study to gain data. The data were analyzed using SWOT analysis which stands for strengths, weaknesses, opportunities, and threats coming from the external factor. The results reveals, from the internal factors, Ijo Gading River possesses some strengths and weaknesses. Its strengths are its historical value, the richness of its culture, and natural landscape which is the traditional fishing boats. Meanwhile its weaknesses are it is not organized well yet, the lack of proper facilities, and the condition of the river that becomes shallower. From the external perspective, Ijo Gading river has several threats and opportunities. The threats are the competitive atmosphere among the same kinds of tourism destinations, its function as a river is destroyed by the activities done around the river, as well as river pollution. But the opportunities are the large empty area, empowering the community, and the community's active participation to develop the tourism activities there.
\end{abstract}

Keyword: Potency, Ijo Gading River, tourism destination,

\section{PENDAHULUAN}

Sungai Ijo Gading sudah tidak asing lagi bagi masyarakat Kabupaten Jembrana. Sungai ini terletak di wilayah Loloan, Kabupaten Jembrana-Bali. Sungai Ijo Gading membagi wilayah Loloan menjadi Loloan Barat dan Loloan Timur dan dihubungkan oleh sebuah jembatan yang bernama Jembatan Syarif Tua (Pramesti, 2014). Sungai Ijo Gading memiliki fungsi penting, namun keberadaannya tidak disadari oleh pemerintah daerah, dan cenderung terabaikan dalam perencanaan kota. Sundra (2017: 9) mengungkapkan kondisi Sungai Ijo Gading sarat dengan beban limbah, sehingga secara visual air berwarna hitam kebiruan. Limbah di Sungai Ijo Gading berasal dari berbagai aktivitas manusia yang meliputi limbah pertanian, limbah rumah tangga, limbah perbengkelan, limbah peternakan (ayam, babi), limbah industri rumah tangga (tahu-tempe), limbah sampah maupun limbah kakus. Akibatnya sungai Ijo Gading menjadi tercemar dan mengalami penurunan kualitas perairan. Padahal Sungai Ijo Gading memiliki posisi yang strategis membelah kota Negara sangat memungkinkan dikemas menjadi suatu daya tarik wisata.

Remaja Loloan Timur yang tergabung dalam kelompok sadar lingkungan (Pokdarling) Loloan ingin menata, menjaga kebersihan dan keasrian Sungai Ijo Gading sehingga dapat dijadikan daerah tujuan wisata yang murah meriah. Muztahidin (2020), selaku Kepala Lingkungan Loloan Timur mendukung upaya Pokdarling Loloan untuk menjadikan sungai Ijo Gading sebagai daya tarik wisata. Menurutnya, lahan di pinggiran sungai Ijo Gading dapat dirancang untuk dijadikan sebagai daya tarik wisata.

Berangkat dari permasalahan tersebut, untuk menjadikan Sungai Ijo Gading sebagai daya tarik wisata yang mampu mendatangkan wisatawan, maka perlu dilakukan suatu penelitian terkait dengan analisis Sungai
Ijo Gading sebagai Daya Tarik Wisata di Kabupaten Jembrana, Bali. Adapun permasalahan yang diangkat yaitu bagaimanakah aspek internal dan eksternal Sungai Ijo Gading sebagai daya tarik wisata di Kabupaten Jembrana, Bali?. Tujuan penelitian ini untuk mengetahui aspek internal yang terdiri dari kekuatan dan kelemahan serta aspek eksternal yang terdiri dari ancaman dan peluang Sungai Ijo Gading sehingga dapat menjadi pertimbangan bagi pihak pengelola, masyarakat, pemerintah maupun pihak terkait lainnya guna menjadikan Sungai Ijo Gading sebagai daya tarik wisata di Kabupaten Jembrana, Bali.

Pengembangan sungai menjadi suatu daya tarik wisata sudah umum dilakukan di Indonesia. Purnaya dan Semara (2018) mengungkapkan Kota Denpasar sudah melakukan penataan terhadap sungai Badung untuk dijadikan sebagai daya tarik wisata di Kota Denpasar. Berbagai upaya dilakukan pemerintah Kota dengan menciptakan Taman Korea, Taman Lumintang dan Taman Pancing. Di sepanjang sungai kawasan Pasar Badung dilengkapi berbagai fasilitas (something to do) seperti tempat duduk, air mancur, lampu taman, jogging track dan tempat memancing, serta membuat alur sungai berkelok agar lebih menarik dan untuk mengantisipasi luapan air Sungai. Pada malam hari kawasan sungai Badung dihiasi dengan lampu warna-warni (something to see) agar suasana menjadi semakin menarik. Pemerintah juga mengadakan event Denpasar Festival yang merupakan perayaan akhir tahun. Di event Denpasar Festival pengunjung dapat menyaksikan (something to see) pesta budaya, konser musik, aktivitas komunitas, seni tabuh dan tari tradisional. Pengunjung juga dapat membeli produk dan kuliner tradisional (something to buy). Tujuan penataan dan penyelenggaraan event Denpasar Festival ini adalah untuk menjadikan sungai Badung sebagai daya tarik wisata sekaligus mengubah citra masyarakat yang menganggap sungai sebagai tempat pembuangan sampah. 
Sungai Loloan juga merupakan sungai yang telah ditata dan dikembangkan menjadi suatu daya tarik wisata di kota Denpasar (Wisudawati, 2017). Sungai Loloan berlokasi di Jalan Sumerta, Desa Sanur Kauh dan termasuk dalam kategori sungai permanen. Sungai ini memiliki air sepanjang tahun sehingga cocok dijadikan sebagai daya tarik wisata. Pemerintah melakukan penataan sungai terkait dengan trend pariwisata yang tidak hanya memberikan suatu daya tarik yang dapat dilihat (something to see) tetapi sekaligus wisatawan dapat melakukan berbagai aktivitas (something to do) seperti jogging, bersepeda, memancing serta didukung fasilitas pendukung lain seperti sepeda bebek air. Sungai Loloan juga diperindah dengan hiasan lampu berwarna warni pada malam hari.

Aspek something to see, something to do dan something to buy merupakan syarat yang harus diperhatikan dalam pengembangan suatu daya tarik wisata agar mampu menarik wisatawan untuk mau datang ke suatu daya tarik wisata (Yoeti, 2010). Suatu daya tarik wisata harus mempunyai something to see atau sesuatu yang bisa dilihat atau dijadikan tontonan oleh wisatawan. Dengan kata lain daya tarik wisata harus mempunyai hal khusus yang dapat menarik minat wisatawan untuk berkunjung. Wisatawan yang berkunjung juga harus bisa melakukan sesuatu atau tersedianya aspek something to do yang berguna untuk memberikan perasaan senang, bahagia, relax melalui penyediaan fasilitas rekreasi seperti arena bermain, tempat makan terutama yang menyajikan makanan khas dari tempat tersebut sehingga mampu membuat wisatawan lebih betah untuk tinggal. Wisatawan yang berkunjung juga harus bisa berbelanja barang atau tersedia aspek something to buy suatu produk yang menjadi ciri khas atau icon dari daerah tersebut, sehingga bisa dijadikan sebagai oleh-oleh.

Yoeti (2010) menambahkan agar suatu daya tarik wisata dapat menarik, maka diperlukan juga kelengkapan dari sarana dan prasarana. Sarana kepariwisataan adalah perusahaan-perusahaan yang memberikan pelayanan kepada wisatawan, baik secara langsung maupun tidak langsung. Sarana kepariwisataan yaitu: a) Perusahaan akomodasi: hotel, losmen, bungalow; b) Perusahaan transportasi: pengangkutan udara, laut atau kereta api dan bus-bus yang melayani khusus pariwisata saja; c) Rumah makan, restaurant, depot atau warung yang berada di sekitar daya tarik wisata dan memang mata pencahariannya berdasarkan pengunjung dari daya tarik wisata tersebut; d) Toko-toko penjual cinderamata khas dari daya tarik wsiata tersebut yang mendapat penghasilan hanya dari penjualan barang-barang cinderamata khas obyek tersebut.

Prasarana kepariwisataan adalah semua fasilitas yang memungkinkan agar sarana kepariwisataan dapat hidup dan berkembang sehingga dapat memberikan pelayanan yang memuaskan kebutuhan wisatawan yang beraneka ragam. Prasarana tersebut antara lain: a) Perhubungan: jalan raya, rel kereta api, pelabuhan udara dan laut, terminal; b) Instalasi pembangkit listrik dan instalasi air bersih; c) Sistem telekomunikasi, baik itu telepon, telegraf, radio, televisi, kantor pos; d) Pelayanan kesehatan baik itu puskesmas maupun rumah sakit; e) Pelayanan keamanan baik itu pos satpam penjaga obyek wisata maupun pos-pos polisi untuk menjaga keamanan di sekitar obyek wisata; f) Pelayanan wistawan baik itu berupa pusat informasi ataupun kantor pemandu wisata; g) Pom bensin

Pengembangan sarana dan prasarana suatu daerah tujuan wisata harus dilakukan dengan sebaik mungkin karena apabila suatu daerah tujuan wisata dapat membuat wisatawan berkunjung dan betah untuk melakukan wisata disana, maka akan menarik banyak minat wisatawan yang diharapkan meningkatkan kesejahterhaan masyarakat lokal.

\section{METODE PENELITIAN}

Lokasi penelitian berada di Sungai Ijo Gading yang terdapat di wilayah Loloan, yang terletak di pusat Kota Negara, Kabupaten Jembrana. Loloan berjarak sekitar 90 km dari pusat kota Denpasar dan berjarak $25 \mathrm{~km}$ dari Pelabuhan Gilimanuk. Kabupaten Jembrana terletak di bagian barat pulau Bali.

Penelitian menggunakan pendekatan kualitatif. Data yang diperoleh dianalisis, diuraikan, dijelaskan dan digambarkan secara sistematis dan objektif sehingga mendapat aspek internal dan eksternal daya tarik wisata Sungai Ijo Gading. Instrumen penelitian utama adalah peneliti sendiri yang dilengkapi dengan alat-alat bantu seperti pedoman wawancara, alat tulis dan alat dokumentasi (Moleong, 2019).

Sumber data yang digunakan yaitu data primer dan data sekunder serta penggunaan purposive sampling untuk menentukan informan sebagai data primer (Sugiono, 2015). Informan yang diwawancarai yaitu Kepala Lingkungan lokasi Sungai Ijo Gading, ketua Pokdarling Ambenan Sungai Ijo Gading sebagai pengelola dan masyarakat sekitar Sungai Ijo Gading. Data sekunder diperoleh dari studi pustaka pada buku, dokumen, artikel, jurnal untuk bahan referensi. Metode pengumpulan data yang digunakan adalah observasi, wawancara, studi dokumentasi dan kepustakaan. (Fatoni, 2011).

Analisis menggunakan analisis SWOT secara kualitatif yang terdiri dari Strengths (kekuatan) dan Weaknesses (kelemahan) lingkungan internal serta Opportunities (peluang) dan Threats (ancaman) lingkungan eksternal (Rangkuti, 2014). Kekuatan (strengths) merupakan faktor lingkungan internal yang dapat mendorong pengembangan daya tarik wisata, juga merupakan alasan seseorang mengunjungi daya tarik wisata. Kelemahan (weaknesses) merupakan faktor lingkungan internal yang dapat menghambat pengembangan daua tarik wisata. Peluang (opportunities) merupakan faktor eksternal yang dapat dimanfaatkan bagi pengembangan daya tarik wisata, jadi peluang adalah halhal positif dari lingkungan eksternal daya tarik wisata yang memberikan dampak positif bagi pengembangan daya tarik wisata. Lain halnya dengan ancaman (threats) yaitu segala sesuatu dari lingkungan eksternal yang dapat menjadi penghambat pengembangan daya tarik wisata.

\section{HASIL DAN PEMBAHASAN}

Potensi dianalis melalui aspek internal dan eksternal. Aspek internal merupakan terdiri dari kekuatan dan kelemahan, yaitu sebagai berikut:

a) Kekuatan (Strengths)

- S1 bernilai historis

Sungai Ijo Gading merupakan sungai yang bernilai historis. Sungai Ijo Gading terletak di wilayah Loloan. Sarlan (2009), mengungkapkan dilihat dari sejarah, 
Loloan merupakan suatu wilayah di Kabupaten Jembrana yang diberikan oleh Raja Jembrana kepada keturunan masyarakat pendatang penyebar Agama Islam permulaan di Bali. Masyarakat pendatang tersebut berasal dari Bugis, Pontianak, Arab dan Melayu yang masuk ke wilayah Jembrana melalui Sungai Ijo Gading. Hal tersebut juga diungkapkan oleh Muztahidin, selaku kepala Lingkungan Loloan Timur.

"Sungai Ijo Gading sudah tidak asing lagi bagi masyarakat Jembrana. Sungai ini merupakan sungai bersejarah. Dulu sungai ini menjadi akses transportasi. Kapal nelayan bisa mencapai daerah Negara, Ibu Kota Kabupaten Jembrana dan berlabuh di tepian Sungai Ijo Gading. Kapal-kapal yang berlabuh datang dari Malaysia, Bugis, Jawa untuk berdagang dan menyebarkan agama Islam di Jembrana" (Muztahidin, 2020)

Berdasarkan hasil wawancara tersebut, kekuatan yang dimiliki Sungai Ijo Gading yaitu terdapat aspek something to do seperti dapat dijadikan sebagai tempat belajar dan mengenalkan kepada generasi muda mengenai bukti sejarah. Hal tersebut didukung oleh adanya beberapa sekolah maupun perguruan tinggi tidak hanya di Jembrana tetapi juga dari luar Bali yang telah mengunjungi sungai Ijo Gading untuk melakukan study tour. Ada juga beberapa sekolah di sekitar wilayah Loloan yang datang ke lokasi Sungai Ijo Gading untuk kegiatan pembelajaran agar muridmurid tidak bosan dengan suasana belajar di dalam kelas.

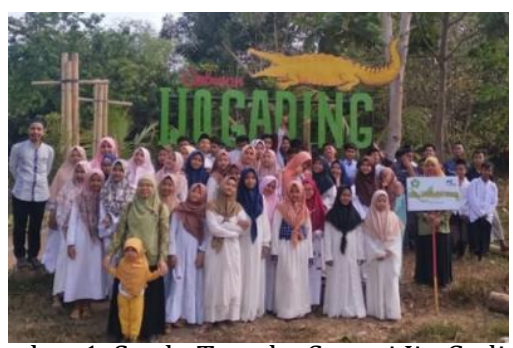

Gambar 1. Study Tour ke Sungai Ijo Gading Sumber: Muztahidin, 2019

- S2 memiliki pemandangan alam dan perahu nelayan

Berdasarkan hasil pengamatan di lapangan, kekuatan (strength) yang dimiliki sungai Ijo Gading yaitu memiliki aspek something to see berupa pemandangan sungai alami aliran air sungai dan pemohonan hijau yang mengelilingi. Sungai Ijo Gading juga masih dimanfaatkan untuk melabuhkan perahu masyarakat sekitar yang berprofesi sebagai nelayan. Perahu nelayan tersebut berwarna-warni dan menarik untuk dilihat. Berikut pernyataan Muztaqim, ketua Pokdarling Ambenan Ijo Gading.

"pengungjung yang datang ke sini ramai biasanya sore hari. Mereka mau melihat sunset disini. Langitnya kelihatan oranye dan ada perahu-perahu nelayan yang berwarna-warni cantik" (Muztaqim, 2020)

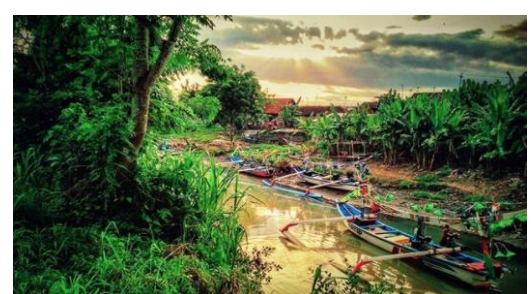

Gambar 2. Pemandangan Alam dan Perahu Nelayan Sumber: Dokumentasi, 2020

- S3 berada di wilayah Loloan yang kaya budaya

Sungai Ijo Gading berada di wilayah Loloan. Loloan merupakan suatu perkampungan yang dihuni oleh masyarakat yang berasal dari Melayu tetapi sudah lama tinggal, menetap dan berbaur dengan masyarakat asli yaitu masyarakat Bali. Masyarakat Loloan memiliki beragam budaya yang merupakan perpaduan antara budaya Melayu dengan budaya Bali. Hasil akulturasi budaya tersebut menghasilkan beberapa kesenian khas Loloan. Berikut pernyataan Muztahidin selaku kepala Lingkungan Loloan Timur:

"Loloan itu sangat kaya. Punya banyak kesenian seperti tari Zapin, kesenian Burdah, Hadrah, Gambus, Gendang, Pencak Silat, Roudat, Marawis, Samroh dan masih banyak lagi" (Muztahidin, 2020)

Beragam kesenian yang dimiliki oleh masyarakat Loloan dapat dijadikan aspek something to see yang mendukung daya tarik wisata Sungai Ijo Gading. Budaya lain yang dimiliki yaitu makanan khas masyarakat Loloan seperti plecing Loloan, sumping kelanjang, bubur kole. Makanan khas masyarakat Loloan dapat dijadikan aspek something to buy yang mendukung daya Tarik wisata sungai Ijo Gading. Dengan meningkatnya kebutuhan wisatawan yang beragam, hampir semua jenis wisata telah ada dengan banyak pilihan namun untuk wisata budaya di Kabupaten Jembrana tidaklah banyak, oleh sebab itu kekayaan budaya masyarakat Loloan merupakan sebuah kekuatan bagi daya tarik wisata sungai Ijo Gading.

b) Kelemahan (Weakness)

- W1 belum ditata dengan baik.

Penataan sungai Ijo Gading saat ini dilakukan oleh Kelompok Sadar Lingkungan (Pokdarling) Ambenan Ijo Gading yang diketuai oleh Muztaqim. Pokdarling Ambenan Ijo Gading merupakan kumpulan remaja Loloan yang peduli dengan lingkungan dan berupaya untuk menjaga dan melestarikan lingkungan di wilayah Loloan. Beragam aksi telah dilakukan oleh Pokdarling Ambenan Ijo Gading, salah satunya yaitu menata sungai Ijo Gading. Awalnya sungai Ijo Gading tidak terawat, ditutupi semak belukar, banyak sampah bahkan tepian sungai Ijo Gading dijadikan tempat pembuangan sampah. Pokdarling Ambenan Ijo Gading dan masyarakat sekitar kemudian tergerak untuk menata tepian sungai untuk dijadikan sebagai lahan terbuka. Mereka melakukan kegiatan bersih-bersih dan mulai menata tepian sungai Ijo Gading. Penataan dilakukan dengan dana swadaya masyarakat dan sumbangan dari beberapa donatur. Sayangnya dana yang diperoleh belum mencukupi untuk mampu menata 
tepian Sungai Ijo Gading secara optimal. Berikut pernyataan Muztaqim, ketua Pokdarling Ambenan Ijo Gading:

"Kami mengumpulkan dana dari masyarakat dan meminta dana dari donatur. Dana yang kami peroleh kami gunakan untuk menata tepian sungai agar dapat dimanfaatkan. Pinginnya sih sebagai tempat wisata, tapi ya syukur-syukur jadi tempat ngumpul anak-anak, pemuda-pemudi di sini. Kami membersihkan lahan dari semak belukar dan tumpukan sampah. Dulu ini semak belukar. Kemudian kami bersihkan dan kami membuat jalan setapak, membuat tangga, menanam pohon tabebuya dan membeli bibit bunga gemitir untuk kami tanam jadikan kebun bunga. Sayangnya dananya terbatas. Masih banyak yang harus ditata, terutama kalau hujan ni, tanahnya benyek. Pinginnya nanti kita pasang paving (Muztaqim, 2020)

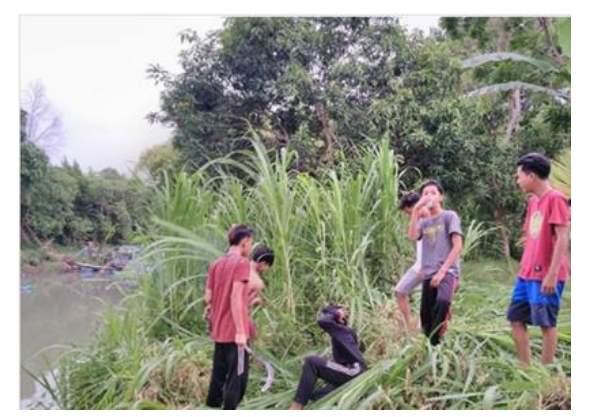

Gambar 4. Aksi Pokdarling Menata Tepian Sungai Ijo Gading

Sumber: Muztahidin, 2018

- W2 belum di dukung oleh sarana dan prasarana pariwisata yang memadai

Yoeti (2010) mengungkapkan agar suatu daya tarik wisata dapat menarik, maka diperlukan kelengkapan dari sarana dan prasarana. Sarana pariwisata seperti akomodasi (hotel, losmen, bungalow), transportasi, rumah makan, restoran, warung, toko cinderamata khas dari daya tarik wisata tersebut. Sedangkan prasarana kepariwisataan seperti perhubungan (jalan raya, pelabuhan udara, Pelabuhan laut, terminal), instalasi listrik dan air bersih, sistem telekomunikasi, pelayanan kesehatan (puskesmas maupun rumah sakit), pelayanan keamanan (pos satpam penjaga obyek wisata), pusat informasi ataupun kantor pemandu wisata dan Pom bensin.

Berdasarkan hasil observasi, sarana pariwisata yang ada di Sungai Ijo Gading hanya ambenan, tempat bermain anak, panggung, tempat duduk, tempat sampah, spot foto, warung kecil yang menjual minuman dan makanan ringan kemasan. Akomodasi seperti penginapan telah tersedia di wilayah Loloan. Toko penjual cinderamata belum ada di lokasi daya tarik wisata. Lahan parkir yang tersedia hanya cukup untuk kendaraan roda dua dan empat. Bus yang datang biasanya parkir di pinggir jalan.

Prasarana pariwisata juga belum lengkap tersedia di Sungai Ijo Gading. Belum ada lampulampu penerangan, saluran air bersih, pos penjaga objek wisata. Puskesmas pembantu tersedia di wilayah Loloan Barat. Pom Bensin ada di wilayah
Loloan Timur. Sungai Ijo Gading memiliki lokasi yang strategis karena terletak di wilayah Loloan yang berada di pusat kota Negara, Kabupaten Jembrana. Akses jalan sangat baik karena melalui jalan utama Denpasar-Gilimanuk. Wilayah ini dekat dengan Pelabuhan Gilimanuk yang merupakan jalur darat menuju ke pulau Jawa. Terminal juga tersedia di kawasan desa Baluk. Sayangnya akses menuju ke Sungai Ijo Gading masih sulit karena belum ada papan petunjuk jalan. Aksesibilitas di daya tarik wisata Sungai Ijo Gading juga masih perlu dibenahi karena ketika hujan, akses jalan menjadi becek dan berlumpur. Masyarakat yang berkunjung rawan terpeleset. Berikut hasil wawancara dengan Muztahidin, kepala Lingkungan Loloan Timur mengenai sarana dan prasarana di Sungai Ijo Gading:

"Sarana dan prasara pariwisata di Sungai Ijo

Gading sangat kurang. Saat ini yang tersedia hanya tempat duduk, ambenan, panggung untuk tempat pertunjukan, warung, taman bermain anak, tempat sampah, spot selfi dan jembatan penghubung taman. Kita masih mengupayakan sarana dan prasarana lainnya seperti WIFI, lampu penerangan, tempat usaha untuk masyarakat, spot selfie diperbanyak, toilet umum, paving. Di sebelah timur ambenan ada lapangan bola. Nanti itu akan kita jadikan lahan parkir. Insya Allah tahun 2020 (Muztahidin, 2020)

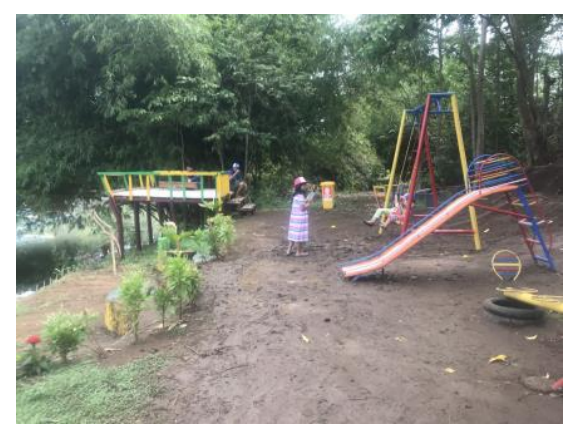

Gambar 5. Ambenan dan Tempat Bermain Anak

Sumber: Dokumentasi, 2020

- W3 Sungai Ijo Gading mengalami Pendangkalan

Sungai Ijo Gading mengalami pendangkalan. Ketika hujan dengan intensitas tinggi, air sungai meluap naik ke permukaan yang menyebabkan tanah menjadi becek dan longsor. Pokdarling Ambenan Ijo Gading telah berupaya untuk membuat sandaran sungai untuk mengantisipasi naiknya air sungai ke permukaan. Aksi Pokdarling tersebut perlu di dukung Pemerintah untuk melakukan pengerukan dasar Sungai untuk mengantisipasi luapan air Sungai terutama ketika curah hujan tinggi. Sayangnya hingga saat ini belum ada respon dari pemerintah setempat. Berikut pernyataan Muztaqim selaku Ketua Pokdarling Ambenan Sungai Ijo Gading:

"Saat ini kami sangat membutuhkan partisipasi Pemerintah terutama untuk pengerukan sungai Ijo Gading. Jika Intensitas hujan tinggi, seringkali sair sungai meluap dan naik ke permukaan sehingga membuat tepi sungai menjadi becek. Sangat mengganggu 
kenyamanan pengunjung. Kami sudah berupaya membuat senderan namun jika tidak ada pengerukan kami khawatir senderan tidak akan mampu bertahan" (Muztaqim, 2020)

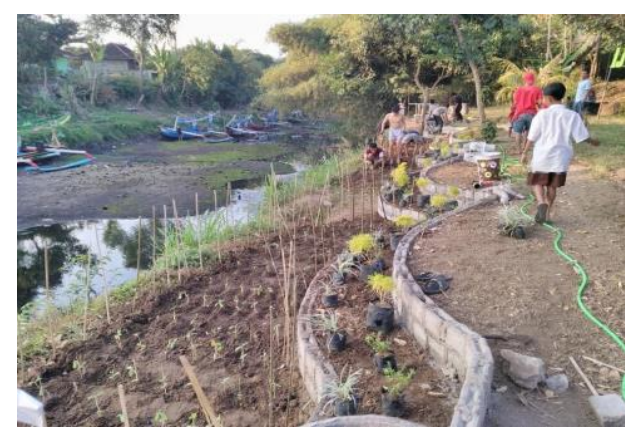

Gambar 5. Senderan Sungai Sumber: Muztahidin, 2018

Analisis eksternal merupakan informasi tentang ancaman dan peluang yang dimiliki sungai Ijo Gading. a) Ancaman (threats)

- T1 Persaingan dengan Daya Tarik Wisata lain yang sejenis

Banyaknya objek wisata air di Kabupaten Jembrana maupun di Bali yang memiliki karakteristik yang berbeda-beda. Jika sungai Ijo Gading dijadikan Daya Tarik wisata maka harus dikelola dan dikembangkan dengan baik agar daya tarik sejenis tidak menjadi ancaman yang cukup besar. Contoh daya Tarik wisata air yang terkenal di Jembrana ialah perancak. Kawasan perancak sudah lebih tertata dibandingkan dengan kawasan sungai Ijo Gading. Di Perancak wisatawan dapat duduk bersantai menikmati keindahan perahu nelayan yang berwarnawarni sambal menyantap hidangan laut yang disajikan di warung-warung makan di kawasan perancak. Berikut pernyataan Muafi selaku ketua pemuda Loloan:

"ada daya Tarik yang menawarkan keindahan perahu-perahu nelayan yaitu di kawasan perancak. Kawasan ini lebih tertata dibanding sungai Ijo Gading. Penjual makanan banyak disana, banyak yang datang kesana" (Muafi, 2020)

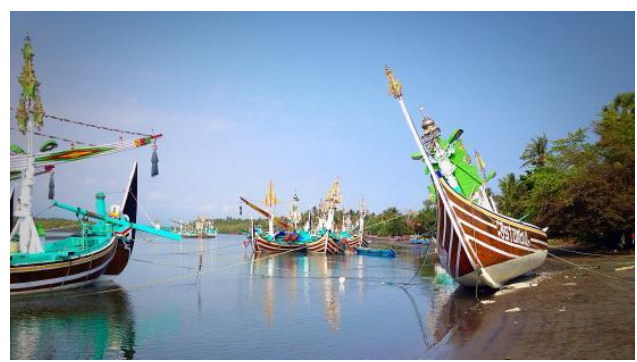

Gambar 6. Daya Tarik Wisata Perancak Sumber: Dokumentasi, 2020

- T2 Fungsi sungai terganggu oleh aktivitas yang berkembang di sekitarnya

Pengembangan aktivitas untuk mendukung daya tarik wisata Sungai Ijo Gading dikhawatirkan akan membawa dampak terhadap fungsi sungai. Namun pihak Pokdarling Ambenan Ijo Gading sebagai pengelola daya tarik wisata Sungai Ijo Gading mengungkapkan bahwa tidak akan membuat aktivitas atau atraksi wisata yang menganggu fungsi sungai, terutama aktivitas nelayan di sungai Ijo Gading. Berikut pernyataan Muztaqim selaku ketua Pokdarling Ambenan Ijo Gading:

"kami ingin menata Sungai Ijo Gading misalnya dengan membangun tempat duduk-duduk untuk wisatawan yang berkunjung sehingga dapat menikmati pemandangan sungai dan perahuperahu nelayan yang lalu Lalang atau bersandar di sungai" (Muztaqim, 2020)

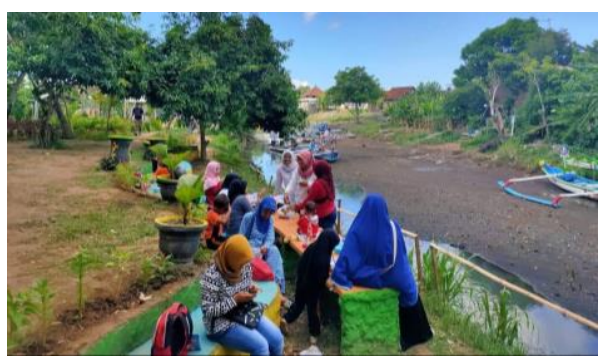

Gambar 7. Pengembangan Aktivitas di Tepian Sungai Sumber: Dokumentasi, 2020

\section{- T3 pencemaran sungai}

Walaupun sungai Ijo Gading sudah ditata dengan baik, namun jika kesadaran masyarakat dalam menjaga kebersihan sungai masih kurang seperti masih membuang sampah maupun limbah rumah tangga dan industry ke sungai maka akan menghambat dan menjadi suatau ancaman dalam upaya menjadikan sungai Ijo Gading sebagai daya Tarik wisata yang mampu mendatangkan wisatawan. Berikut pernyataan Muafi, ketua Pemuda Loloan:

"masyarakat sekitar sudah kami ajak untuk senantiasa menjaga kelestarian lingkungan salah satunya dengan menjaga sungai Ijo Gading yang merupakan sungai bersejarah dan memiliki potensi untuk dijadikan sebagai daya Tarik wisata. Sejauh ini msayarakat mendukung upaya kami. Hal tersebut terlihat dengan semakin berkurangnya sampah di sungai Ijo Gading" (Muafi, 2020)

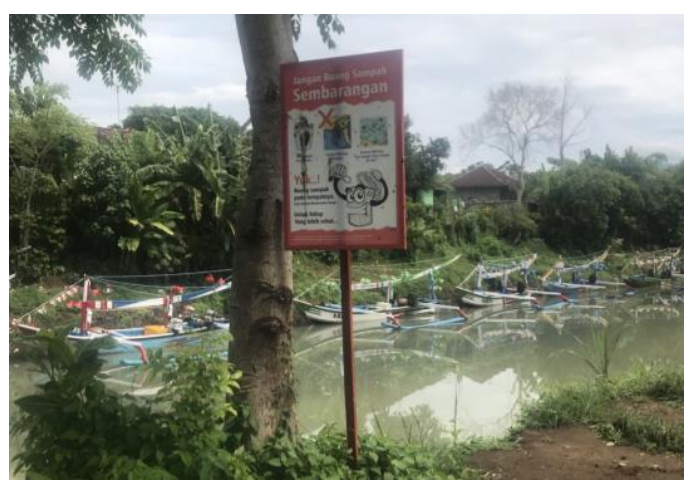

Gambar 8. Himbauan Menjaga Lingkungan Sungai Ijo Gading

Sumber: Dokumentasi, 2020

b) Peluang (Opportunity)

- 01 Lahan yang luas dan kosong

Tepian Sungai Ijo Gading merupakan lahan yang luas dan kosong sehingga lahan tersebut berpotensi 
untuk dikembangkan. Dengan lahan yang luas tersebut, pengelola bisa melakukan inovasi-inovasi seperti penambahan tempat atraksi/kegiatan, pembangunan toko-toko untuk masyarakat berjualan maupun fasilitas lainnya yang mendukung Sungai Ijo Gading sebagai daya tarik wisata. Berikut pernyataan Muztahidin selaku kepala Lingkungan Loloan terkait dengan lahan untuk pengembangan daya tarik wisata sungai Ijo Gading:

"Lahan yang kita tata dan mau kita jadikan daya tarik wisata ini merupakan lahan milik pemerintah yang digunakan sebagai tempat pembuangan sampah. Lahan tersebut kita manfaatkan, kita bersihkan, kita tata dan jadikan sebagai daya tarik wisata. Lahannya masih sangat luas dan memungkinkan untuk pengembangan nantinya misalnya mau kita bangun rumah panggung nanti di sana. Lahan masih cukup" (Muztahidin, 2020)

\section{- 02 Dapat memberdayakan masyarakat}

Kegiatan pariwisata akan memperluas kesempatan tenaga kerja baik dari kegiatan pembangunan sarana dan prasarana maupun dari berbagai sektor usaha yang langsung maupun yang tidak langsung berkaitan dengan kepariwisataan. Kegiatan pariwisata juga dapat memberikan sumbangan terhadap penerimaan daerah bersumber dari pajak, retribusi parkir dan karcis atau dapat mendatangkan devisa dari para wisatawan mancanegara yang berkunjung. Adanya pariwisata juga akan menumbuhkan usaha-usaha ekonomi yang saling merangkai dan menunjang kegiatannya sehingga dapat meningkatkan pendapatan masyarakat seperti berjualan makanan, minuman dan souvenir. Masyarakat juga bisa melakukan aktivitas wiraswasta seperti penyediaan tempat tinggal sementara (penginapan) dan pelayanan yang berhubungan dengan hal itu, seperti penyediaan makanan dan minuman (food and beverage). Berikut pernyataan Muztahidin selaku kepala Lingkungan Loloan:

"harapan kami dengan dijadikannya sungai Ijo Gading sebagai daya Tarik wisata adalah bertambahnya kesadaran masyarakat untuk menjaga kelestarian sungai. Selain itu kami juga berharap akan ada pemasukan bagi masyarakat sekitar. Masyarakat dapat berjualan makanan dan minuman maupun produk khas Loloan" (Muztahidin, 2020)

- 03 Masyarakat aktif dan mendukung pengembangan pariwisata di daerahnya

Masyarakat Loloan merupakan masyarakat yang memiliki keberagaman budaya. Budaya tersebut ingin mereka lestarikan dengan secara rutin menggelar suatu festival budaya yang diprakarsai oleh Gerakan Pemuda Loloan (GPL). Masyarakat Loloan turut serta dalam festival budaya mulai dari orang tua, ibu-ibu sampai anak-anak turut berperan dalam event budaya. Berikut hasil wawancara dengan Muafi selaku ketua GPL (Gerakan Pemuda Loloan)
"Gerakan Pemuda Loloan merupakan suatu kelompok yang diprakarsai oleh pemudapemudi Loloan Timur. Kelompok ini berupaya untuk melestarikan dan memperkenalkan budaya Loloan terutama kepada generasi muda Loloan dan masyarakat sekitar. Adapun aksi yang dilakukan yaitu dengan rutin menggelar festival budaya Loloan yang diikuti oleh pemuda-pemudi dan masyarakat Loloan. Sayangnya tempat penyelenggaraan tersebut belum ada. Biasanya kita pentaskan di jalan kita membangun panggung" (Muztahidin, 2020)

Muztahidin selaku Kepala Lingkungan Loloan Timur menambahkan bahwa pihaknya mendukung aksi GPL untuk rutin menggelar festival budaya guna melestarikan dan memperkenalkan kebudayaan Loloan kepada generasi muda dan masyarakat luas, salah satunya yaitu dengan mengajak GPL dan masyarakat sekitar untuk membersihkan area tepian sungai Ijo Gading dan memanfaatkannya sebagai tempat untuk menggelar festival budaya Loloan maupun untuk tempat mengasah kreativitas pemuda-pemudi Loloan. Berikut pernyataannya:

"Saya sangat mendukung pemuda-pemudi Loloan. Mereka ingin memperkenalkan budaya Loloan terutama kepada generasi muda Loloan. Sayangnya tempat tidak ada. Saya berpikir di tepian sungai Ijo Gading ada lahan kosong cukup luas. Selama ini dijadikan tempat pembuangan sampah. Kenapa gak kita manfaatkan untuk tempat main anak-anak, nongkrong-nongkrong, main musik atau mengasah kreativitas. Pemudapemudi di sini kreatif lho. Saya ajak pemuda dan masyarakat untuk bersih-bersih. Kami bangun panggung dari kayu-kayu bekas. Ya lumayanlah ada sekarang tempat buat anak-anak. Bisa juga untuk tempat pertunjukan budaya. Kami biasanya menggelar opera Melayu yang menampilakn budaya Loloan Jaman Lame. Menampilkan budaya-budaya Loloan yang sudah hampir-hampir punah. Nah bisa kita tampilkan di sini" (Muztahidin, 2020)

Adanya pertunjukan budaya yang ditampilkan oleh pemuda-pemudi Loloan di tepian sungai Ijo Gading merupakan aspek something to see yang mendukung sungai Ijo Gading sebagai daya tarik wisata. Apalagi budaya tersebut sangat khas karena hanya dimiliki oleh masyarakat Loloan. 


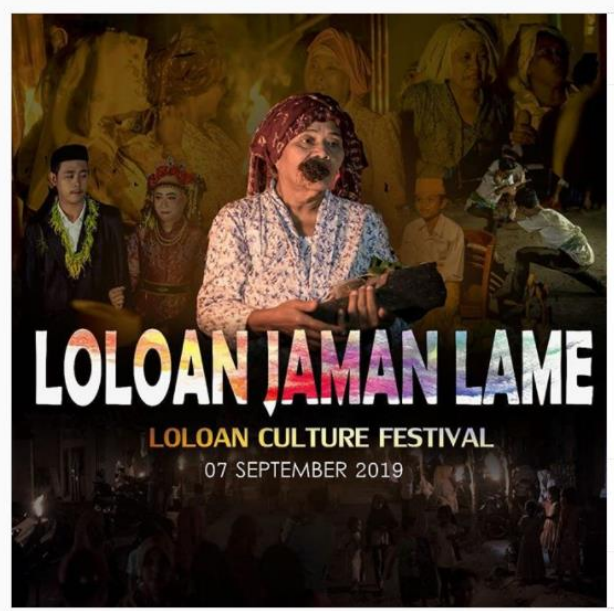

Gambar 9. Festival Budaya Loloan Sumber: Muztahidin, 2018

\section{KESIMPULAN DAN REKOMENDASI}

\subsection{Kesimpulan}

Berdasarkan hasil analisis diperoleh kesimpulan bahwa Sungai Ijo Gading memiliki kekuatan, kelemahan, ancaman dan peluang dlama upaya menjadikan sungai Ijo Gading sebagai daya Tarik wisata. Kekuatan yang dimiliki Sungai Ijo Gading yaitu bernilai historis karena merupakan sungai yang menjadi cikal bakal masyakarat Loloan, memiliki pemandangan alam dan perahu nelayan yang berwarna warni dan berada di wilayah Loloan yang kaya budaya. Budaya-budaya Loloan tersebut mampu menjadi atraksi/kegiatan yang ditampilakn di daya Tarik wisata sungai Ijo Gading.

Kelemahan yang dimiliki sungai Ijo Gading yaitu penataan. Ancaman yang dimiliki sungai Ijo Gading yaitu adanya persaingan dengan daya Tarik wisata lain yang sejenis misalnya daya Tarik wisata Perancak. Peluang yang dimiliki sungai Ijo Gading yaitu memiliki lahan yang luas

\section{DAFTAR PUSTAKA/REFERENSI}

Fatoni, Abdurrahman. (2011). Metodologi Penelitian dan Teknik Penyususna Skripsi. Jakarta: Rineka Cipta

Moleong, L. J. (2019). Metodologi penelitian kualitatif. Bandung: Rosdakarya

Pramesti, Dinar Sukma. (2014). Sistem Spasial dan Tipologi Rumah Panggung di Desa Loloan, Jembrana (Bali). EJurnal: Ruang-Space (Jurnal Lingkungan Binaan). Vol 1 No.1 April 2014. Hal 67-84

Purnaya dan Semara. (2018). Implementasi Kebijakan Pemerintah Terhadap Penataan Sungai Badung dalam Upaya Pengembangan Pariwisata di Kota Denpasar. Jurnal Ilmiah Hospitality Management. Vol.8 No.2 Juli 2018.

Rangkuti, Freddy. (2014). Analisis SWOT: Teknik Membedah Kasus Bisnis. Jakarta. PT Gramedia Pustaka Utama

Sarlan (2009) Islam di Bali: Sejarah Masuknya Agama Islam ke Bali Biang Bimas Islam dan Penyelenggaraan Haji Kantor Wilayah Departemen Agama Provinsi Bali. Program Peningkatan

Sugiyono. (2015). Metode Penelitian Kuantitatif, Kualitatif dan R\&D. Bandung: Alfabeta

Sundra, I Ketut. (2017). Kondisi Dan Status Lingkungan Hidup Di Kabupaten Jembrana. Denpasar: Jurusan Biologi Fakultas Matematika Dan Ilmu Pengetahuan Alam Universitas Udayana

Wisudawati, Ni Nyoman Sri. (2017). Pengembangan Daya Tarik Wisata Sungai Di Kota Denpasar Melalui Pemberdayaan dan kosong sehingga memudahkan dalam perancangan dan pemberdayaan masyarakat.

\subsection{Rekomendasi}

Berdasarkan simpulan yang telah disampaikan, maka dapat diajukan beberapa rekomendasi kepada pengelola Pemerintah, pihak swasta dan masyarakat sekitar. Pengelola diharapkan mampu menjaga, melestarikan dan merawat sungai Ijo Gading sebagai warisan sejarah dan budaya. Memberikan terobosan atraksi berbasis budaya Loloan sebagai daya tarik lain seperti pementasan tari Zapin, kesenian Burdah, Hadrah, Gambus, Gendang, Pencak Silat, Roudat, Marawis, Samroh maupun opera Melayu. Membenahi sektor infrastruktur sarana dan prasana untuk menunjang kebutuhan dan memuaskan pengunjung. Membangun dan merencanakan fasilitas penunjang agar lebih banyak menarik pengunjung. Adanya promosi dan pengelolaan yang tepat diharapkan mampu pemanfaatan teknologi untuk media promosi, kesan positif dari wisatawan yang pernah berkunjung, perluasan segmen wisatawan dari berbagai meningkatkan jumlah kunjungan wisatawan.

Mewujudkan pariwisata budaya diharapkan kemauan pemerintah untuk berperan aktif dalam pengembangannya. Mendukung dan merencanakan perawatan, perbaikan dan pembangunan yang dilakukan pengelola sehingga Sungai Ijo Gading menjadi daya Tarik wisata unggulan di Kabupaten Jembrana. Masyarakat Loloan juga diharapkan tetap menjaga dan mempertahankan potensi yang dimiliki seperti keindahan alam, dan bangunan bersejarah sebagai daya tarik wisata tanpa banyak melakukan perubahan fisik.

Pariwisata berkelanjutan dapat diwujudkan dalam pariwisata budaya jika terdapat visi yang serupa antar komponen. Pemahaman tentang pengelolaan pariwisata yang berkelanjutan perlu dimengerti oleh masyarakat dalam menghadapi dampak positif dan negatif dari kegiatan pariwisata yang sulit dihindari tetapi dapat diupayakan antisipasinya.

Masyarakat (Studi Kasus Sungai Loloan Di Kawasan Mertasari, Sanur Kauh). Jurnal Ilmiah Hospitality Management Vol. 8 No. 1, Desember 2017. P: 23-28

Yoeti, Oka A. (2010). Dasar-Dasar Pengertian Hospitality dan Pariwisata. Bandung: PT.Alumni 